[Н.В. Санина, Т.А. Степанова, Е. Б. Панина и др.]. - Воронеж: Воронежский государственный аграрный университет; 2015. - 47c.

3. Сидельникова А.В. Анализ эффективности подсолнечника по Воронежской области / А.В. Сидельникова, Т.А. Степанова // Политэкономические проблемы развития современных агроэкономических систем. Под общ. Ред. Е.Б. Фалькович, Е.А. Мамистова. - 2018 - С. 151-156.

4. Степанова Т.А. Анализ производства подсолнечника и пути его роста на примере предприятий Воронежской области / Т.А. Степанова, А.С. Наконечная // Политэкономические проблемы развития современных агроэкономических систем. Под общ. Ред. Е.Б. Фалькович, Е.А. Мамистова. - 2018 - С. 139-144.

5. Степанова Т.А. Оценка роли для экономики, состояние и развитие производства подсолнечника в РФ / Т.А. Степанова, Л.Н. Измайлова, Я.В. Лен // Перспективы развития науки и образования. Под общ. Ред А.В. Туголукова. - 2018 - С. 178 - 186.

6. Хаустова Г.И. Повышение эффективности производства семян подсолнечника в рыночных экономических условиях / Г.И. Хаустова, Л.А. Шатохина // Современные тенденции развития технологий и технических средств в сельском хозяйстве: Материалы междунар. науч.- практич. конф.,посвящ. А.П. Тарасенко, докт. техн. наук, заслуженного деятеля науки и техники РФ, профе. Каф. сельскохозяйственных машин Воронеж. гос. аграр. ун-та имени императора Петра I; Под общ. Ред. Н.И. Бухтоярова, В.И. Оробинского, И.В. Баскакова. - 2017 - С. 196-200.

\title{
Колесникова М.М.
}

\section{Наличный и безналичный расчёт: развитие цифровизации в России}

Сибирский федеральный университет (Россия, Красноярск)

doi: $10.18411 / 1 j-07-2020-117$

idsp: ljournal-07-2020-117

\section{Аннотация}

Анализировано количество безналичных транзакций в России за последние 10 лет. Определены основные преимущества и недостатки видов денег, использующихся для оборота. Намечено дальнейшее развитие формы денежного расчёта. Рассмотрены возможные последствия таких изменений.

Ключевые слова: безналичный расчёт, электронные деньги, наличные денежные средства, банковские операции, количество транзакций

\section{Abstract}

It analyzes the number of cashless transactions in Russia over the past 10 years. The main advantages and disadvantages of the types of money used for turnover are identified. The further development of the form of cash settlement is outlined. The possible consequences of such changes are considered.

Keywords: bank transfer, electronic money, cash, banking operations, number of transactions

В период продвижения информационных технологий некогда принятые социальные установки меняются очень быстро. В последние годы одной из важных тем для обсуждения в мировом финансовом дискутировании является развитие безналичного расчёта как основного средства платежа. Движение в сторону безналичной оплаты официально является одним из приоритетов финансового регулирования в ряде стран, как развитых, так и развивающихся. Одновременно большое количество частных компаний и бизнес-ассоциаций работает над созданием и продвижением необходимых для этого инструментов и платформ. И интересно то, что во многих странах наблюдается недостаточный темп развития в этой области. Достаточное количество препятствий, наряду с простым человеческим незнанием, замедляют выталкивание из оборота наличных денег. Россия - не исключение в этом. В стране происходит довольно медленное развитие безналичного расчёта — это приводит к выводу о том, что несмотря на все преимущества безналичной оплаты, люди до сих 
пор не готовы доверить свои сбережения банку и электронным платформам. Поэтому наличные деньги остаются самым распространенным вариантом оплаты в России: ими пользуется на постоянной основе $89 \%$ населения [1]. Только $2 \%$ населения полностью отказались от наличных, свидетельствуют результаты опроса исследовательской лаборатории Левада-центра Levada Lab (Исследовательская лаборатория для бизнеса Levada Lab. Ее основное направление - исследования пользовательского опыта (UX), этнография и продуктовая аналитика).

Большая доля людей не могут полностью отказаться от наличных по некоторым причинам: отсутствие интернета в удаленных населенных пунктах, отсутствие реформирования для приема карт в малых торговых точках и предприятиях сферы услуг. В $12 \%$ российских магазинов, ресторанов, кафе и отелей сегодня нельзя расплатиться картой, если судить по данным Сбербанка. Также среди причин редкой оплаты картой присутствует страх мошенничества. Четыре человека из десяти, которые не оплачивают покупки картами, боятся мошенников, как отмечает руководитель проектов отдела социально-экономических исследований Левада-центра Ольга Караева. Кроме того, обществу еще нужно по-настоящему привыкнуть к безналичной оплате, это должно войти в привычку.

Тем не менее, постепенный, но медленный переход на безналичный расчёт все же существует. В третьем квартале 2019 года почти 49\% всех товаров и услуг в стране было оплачено безналичным расчетом.

В марте 2019 года ВЦИОМ (Всероссийский центр изучения общественного мнения, ВЦИО́М (до 1992 года - Всесоюзный) - старейшая российская исследовательская организация, регулярно проводящая социологические и маркетинговые исследования на основе опросов общественного мнения) опубликовал результаты опроса, причастного к банковским картам. $69 \%$ опрашиваемых заявили, что за последние четыре-пять лет стали пользоваться картами намного чаще, еще $18 \%$ немного чаще. Три четверти опрошенных сообщили, что при условии наличия и карты, и бумажных денег, они воспользуются картой.

За два года количество россиян, которые используют для оплаты только безналичные инструменты, может вырасти из-за молодых поколений, не начавших активно пользоваться картами, но уже привыкших к технологиям во всех сферах жизни. По данным Центрального банка России [2], более 90\% операций по картам граждан России в первом полугодии 2019 года пришлось именно на оплату товаров и услуг, а также переводы с карты на карту/банковский счет/вклад. При этом и по объему такие операции занимают достаточно большую долю рынка - 68\%. В целом за январьиюнь 2019 года физические лица использовали свои карты 19,2 млрд раз на общую сумму более 40 трлн рублей. Объем эмиссии активных карт (с помощью которых была совершена хотя бы одна операция в отчетном периоде) на конец июня составил почти 183 млн, увеличившись по сравнению с идентичным периодом прошлого года более чем на $8 \%$. Доля перехода населения на безналичную оплату увеличивается с каждым годом, и на 1 июля 2019 года на 1 млн жителей приходилась 21 тыс. устройств по приему платежных карт, что показывает несомненное развитие платежного реформирования. Кроме того, анализируя количество счетов (Счета, открытые клиентам (резидентам и нерезидентам) в валюте Российской Федерации, с которых имеется возможность осуществлять платежи, в том числе с использованием расчетных и кредитных карт. Счета, открытые кредитным организациям (филиалам), не учитываются), открытых учреждениями банковской системы (Учреждения Банка России, кредитные организации, филиалы кредитных организаций) за последние 10 лет, можно сделать вывод о постепенном увеличении общего количества счетов с каждым годом. Так, в 2010 году общее количество счетов составляло около 526 тыс. на ноябрь, а на ноябрь 2019 года эти цифры изменились до 933 тыс. Можно сказать, что за год количество счетов увеличивается в среднем на 30-60 тыс. Также при анализе структуры переводов денежных 
средств, осуществленных через платежную систему Банка России, сразу видно, что с 2014 года ежегодное увеличение переводов денежных средств растет в процентном соотношении. Так, в 2014-2015 гг. переводы увеличились на 2\%, а в 2018-2019 гг. уже на $7 \%$, что говорит о постепенном увеличении темпов роста переводов денежных средств. Следовательно, можно сделать вывод, что за последнее время с ускорением технологического прогресса люди стали более охотно пользоваться безналичным расчетом и различными электронными операциями, связанными с деньгами.

Тем не менее, стоит рассмотреть основные преимущества и недостатки той или иной формы денег, чтобы понять, как скоро наличный расчет перестанет преобладать над безналичным и перестанет ли? Итак:

1) Удобство в применении. Самым простым вариантом расчетов для всех торговых точек, где действует расчет с продавцом лично, являются наличные деньги: они не требуют присутствия каких-то технических устройств, интернета, а также ввода паролей, которые можно забыть. Но при этом оплата картой или телефоном в последние годы перешла на новый уровень, ведь для оплаты достаточно просто приложить карточку, а не ждать, пока тебе выдадут сдачу, как это работает с наличными.

2) Распространенность или применимость. Что касается данного критерия, здесь, безусловно, приоритет отдается наличным деньгам, так как большинство граждан России пользуются в большей степени наличными деньгами. Кроме того, до сих пор существуют торговые точки, которые не имеют специальных терминалов для безналичной оплаты.

3) Безопасность. Определенно отдать преимущество одному из видов денег сложно. С одной стороны, наличные деньги могут подвергаться подделке и краже, а с другой стороны, с безналичными деньгами часто любят работать мошенники: это и хищение банковской карты, и средств с банковского счета (в том числе, незаконного списания средств со счета), и пр. Но плюс у безналичных денег в данной ситуации все же есть: при выполнении определенных действий деньги можно вернуть, что крайне редко происходит в случае с наличными деньгами.

4) Срок действия. Срок действия наличных денег зависит от износоустойчивости бумажных и металлических денег, а безналичных - от срока действия карты, который установлен системой или договором. Все же в данной ситуации электронные деньги предпочтительнее, так как вероятность потерять или порвать купюру больше, нежели забыть о сроке действия карты.

5) Удобство транспортировки. Актуально, если речь идет о транзите денежных средств (например, при поездке за границу). С помощью банковской карты можно «доставить» любую сумму без препятствий, чего нельзя сделать наличными деньгами [3]. Во-первых, когда требуется перевезти крупную сумму, это неудобно, вовторых, потребуется предоставление оглашения.

6) Контроль над средствами. Наличные можно пересчитать, а по карте всегда можно узнать остаток из мобильного банка, в любом случае, лимит растрат ограничен суммой имеющихся средств. Сложности с контролем над тратой средств могут возникнуть при использовании банковских карт, которые позволяют выходить за пределы остатка по счету. При ошибке в своих материальных возможностях, необходимо будет вовремя внести перерасходованную сумму на счет и уплатить проценты за её использование.

7) Способность приносить доход. Наличные деньги не способны принести какой-либо доход, ведь они всего лишь могут лежать в кошельке или кармане, в то время как условиями некоторых договоров банковского счета оговаривается начисление процентов на остаток, который находится на счете.

8) Содержание. Это относится к безналичным средствам, доступ к которым производится при помощи банковской карты. В данном случае дополнительные траты 
возникают в виде комиссии за переводы, за обслуживание карты, за информирование, за снятие наличных в «других» банкоматах. И это, пожалуй, главный недостаток безналичных средств.

Тем не менее, можно сказать, что, несмотря на некоторые недостатки, безналичный расчет на данный момент намного удобнее. Тем более, развитие технологий способствует ускорению цифровизации, поэтому в будущем получится избавиться от особенно значимых недостатков и недоработок. Также, анализируя мировые события, произошедшие в 2020 г., можно с уверенностью сказать о том, что под конец года процент людей, использующих безналичный расчет, увеличится. Дело не только в пандемии COVID-19 и изолировании друг от друга, когда у людей нет возможности заплатить наличными по понятным причинам. Но и в том, что человек, находясь в домашней обстановке без возможности выхода на улицу, вынужден пользоваться электронными деньгами, чтобы удовлетворять свои потребности, а это, в свою очередь, может привести к постепенному и полному переходу на безналичный расчет. Кроме того, когда удастся победить вирус с помощью изобретенной вакцины, общество уже не будет прежним, ускоренная цифровизация продолжится, ведь изоляция дала людям время не только на саморазвитие, но и на то, чтобы осознать всё удобство и мобильность электронных платформ.

Несомненно, для достижения перехода к безналичной экономике недостаточно опираться только на население, нужен «правительственный толчок» [4]. Именно государство получает большую часть эффектов транспарентности. Поэтому с этой точки зрения нынешняя установка ряда административных органов на стратегические действия, которые нацелены на увеличение безналичного оборота, представляется совершенно обоснованной. Важным препятствием к развитию рынка является отсутствие согласованности действий прямых и косвенных контролеров систем платежей, при которой последние выступают в роли невольных создателей правительственных барьеров для основных участников рынка. Таким образом, эффективное и равновесное решение вопросов, которые связаны со сложившимися барьерами в области безналичного оборота, способно ускорить динамику процессов на 80-120\%. Можно сделать вывод, что России нужно время, много времени, чтобы достичь уровня стран -лидеров по безналичным операциям.

$$
* * *
$$

1. Бизнес-телевидение «РБК» [Электронный ресурc] - Режим доступа: https://www.rbc.ru/

2. Официальный портал Банка России - Режим доступа: https://cbr.ru/

3. Банковский информационно-аналитический портал - Режим доступа: http://www.sotnibankov.ru/

4. Денисова Н.Н., Рулинская А.Г. - РАЗВИТИЕ БЕЗНАЛИЧНОЙ ЭКОНОМИКИ В РОССИИ - 2016 г., 28-29 стр.

Лызлова Л.Н.

Проблемы учета затрат в экологическом управленческом учете

Новосибирский государственный университет экономики и управления (Россия, Новосибирск)

doi: $10.18411 / \mathrm{j}-07-2020-118$

idsp: ljournal-07-2020-118

\section{Аннотация}

Экологический учет- это система, которая используется для выявления, организации, регулирования и представления данных и информации о состоянии окружающей среды в натуральных и стоимостных показателях.

Основанная на тех же принципах, что и все системы учета, система экологического учета дает объективную картину состояния и динамики природного 